\title{
CINE
}

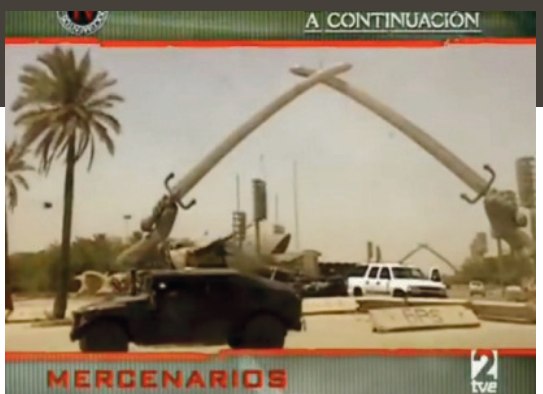

TÍTULO ORIGINAL,

"Mercenarios en la guerra de Irak"

ANO: 2007, DURACION: 50 minutos y 27 segundos,

PAÍS: España,

PRODUCTORES: Documentos TV, Corporación de

Radio y Televisión Española,

GÉNERO: Documental.

\section{Mercenarios en la guerra de Irak}

En este documental se expone el tema de los mercenarios, considerándolos hombres de fortuna que han existido desde la batalla de Decades, la cual tuvo lugar en el año 1.200 antes de Cristo, hasta la actualidad. Irak es uno de los países que más se ha servido de estas empresas contratistas. En Irak hay más contratistas civiles armados que soldados de todos los países juntos, excluyendo a Estados Unidos.

En la actualidad estas empresas se consideran contratistas de seguridad privada. Existen más de 20.000 empresas operando en más de cincuenta países, obteniendo ingresos alrededor de los cien mil millones de dólares anuales. Son conocidas también como compañías militares privadas, las cuales contratan a personas civiles con experiencia en el rubro, ex militares y agentes que hayan estado en puestos de áreas tácticas. Además, sus empleados tienen que ser profesionales y perseverantes.

Los mercenarios son personas que no están sujetas a las leyes de Irak, pueden actuar con impunidad, no cumplen reglas ni normas como cualquier otro civil -las únicas que cumplen son las que siguen en el grupo de convivencia como mercenarios-, sus turnos de trabajo son rotativos, utilizan armamento sofisticado igual o mejor que el que utilizan los militares, entre los cuales están las metralletas, ametralladoras de calibre grande montadas en vehículos, ametralladoras ligeras PKM y ametralladoras AK 47, rifles de todo tipo y automóviles blindados. Su motivación es el beneficio personal sin tener en cuenta valores ni principios.

Los mercenarios operan en zonas en crisis y zonas de combate, debido a la naturaleza del negocio de las empresas contratistas.

Este documental presenta la realidad a la que se enfrentan los mercenarios, cómo son reclutados y entrenados rigurosa y profesionalmente para enfrentarse a ganar o perder su vida a cambio de un beneficio económico y, a la vez, defender a quien le encomienden a cambio de un salario. Es un trabajo muy arriesgado.

En la actualidad se ha vuelto un negocio lucrativo para diferentes empresas contratistas que se dedican a explotar esta actividad. A estas empresas no les afecta en lo absoluto que la economía se debilite, todo lo contrario, es cuando más obtienen ganancias. 


\section{CINE}

Los mercenarios son personas civiles armadas, con mejor entrenamiento que el de los militares, están dispuestos a combatir por aire, tierra y mar, incluso por una causa que no es la de su país.

Se dividen en tres categorías:

1. Servicios no letales. Este grupo da apoyo logístico en operaciones militares y en misiones del mantenimiento de paz.

2. Asesoramiento militar. Este grupo se encarga de entrenar y llevar al campo de batalla a los futuros mercenarios.

3. Servicios privados. Trabajan generalmente para el gobierno, su misión es aplicar y cambiar estrategias.

Los mercenarios son profesionales que arriesgan mucho su vida y están dispuestos al sacrificio, entendido como la posibilidad de ser muertos en pos del cumplimiento de un objetivo militar.

Las normas de compromiso que tienen y que deben cumplir para sobrevivir y mantenerse activos como mercenarios son:

- $\quad$ Protegerse a sí mismos.

- Autodefensa/protección de su identidad, ya que se les permite proteger su nombre real o el de la organización que los contrate.

- Protección a civiles bajo amenaza de muerte inminente cuando estos han contratado sus servicios.

Lo impactante de este documental es ver como personas inocentes pierden la vida ante el escenario de una guerra, mientras las compañías de contratistas de seguridad privada se enriquecen; pero lo más importante, es darse cuenta que la vida es un círculo, donde lo que se siembra se cosecha, ya que así como los mercenarios son capaces de matar a de personas inocentes, de esta misma manera mueren en el cumplimiento de su deber.

Por lo tanto, los mercenarios son grupos de personas que deciden iniciar una nueva vida formando parte de una nueva sociedad de profesionales en el rubro, dejando a su familia, su país de origen para mejorar las condiciones económicas y cubrir con sus necesidades familiares. Se debe tomar en cuenta que pertenecer y ser contratado por una empresa militar de seguridad privada solo es una forma de trabajo, que para algunos tendrá una perspectiva positiva y para otros será negativa. Por supuesto que los mejores beneficiados al brindar este tipo de servicio son los asociados y propietarios de las empresas de seguridad privada. 